\title{
A MILP Model for Enhancing Wastewater Networks by Introducing Reclaimed Wastewater Usage
}

\author{
Fabian Lechtenberga, Ana Somoza-Tornosa,b, Antonio Antonio Espuna ${ }^{a}$, Moisès Graells** \\ aDepartment of Chemical Engineering, Universitat Politècnica de Catalunya, Barcelona 08019, Spain \\ ${ }^{b}$ Renewable and Sustainable Energy Institute, University of Colorado Boulder, Boulder, Colorado 80303, United States \\ *moises.graells@upc.edu
}

\begin{abstract}
Wastewater treatment plants (WWTPs) are an example of available but underutilized waste-to-resource processes. Economic benefit opportunities can be generated through the design and operation of WWTPs following a circular economy policy. At the same time, the environmental performance is also enhanced, since water scarcity is counteracted by replacing freshwater usage with reclaimed water. In this work, we develop a MILP mathematical model representing the main characteristics of multi-contaminant wastewater exchange networks and validate it through a case study that is inspired of a WWTP located in Barcelona, Spain. As a result, we find an optimal network that can reduce the water treatment cost from $0.404 € / \mathrm{m}^{3}$ to 0.312 $€ / \mathrm{m}^{3}$. Moreover, the model allows considering the possibility of retrofitting the existing WWTP by constructing an additional treatment line and drawing the barriers for this line to achieve the targeted wastewater treatment cost. These results demonstrate that changing the role of WWTPs from an "end-of-the-pipe" solution towards a waste-to-resource route bears an unexplored potential that should be considered by all actors in the water market.
\end{abstract}

Keywords: Wastewater Treatment Plants, Water Exchange Network, Circular Economy, Waste-to-Resource, Optimization

\section{Introduction}

The recycle and reuse of wastewater has been widely studied during the last half century. Mathematical formulations for its intra-plant implementation are state-of-the-art (Karuppiah and Grossmann, 2006) and within the last two decades these models have been extended to consider exchanges in eco-industrial parks (Salas et al., 2020). Very recently, a study by SomozaTornos et al. (2019) showed that also municipal WWTPs can generate benefit by targeting wastewater exchange in the context of circular economy. A recent trend in sludge valorization technologies further fosters WWTPs to generate symbiotic revenues (Guerra-Rodríguez et al., 2020). When overcoming the health related concerns of using regenerated water, there is an unexplored economic and environmental potential that can be exploited by identifying customers and retrofitting WWTPs in order to make use of reclaimed wastewater. In this work we reveal this potential by developing an optimization model for the operation of WWTPs considering the possibility of introducing new treatment lines.

\section{Problem Statement}

Given a set of customers $K$ with a water demand $D_{k}$ and quality constraints $\mathrm{c}_{\mathrm{j}, \mathrm{k}}$ for a set of contaminants $\mathrm{J}$, the problem consists of finding the optimal supply network (distribution) that minimizes the water treatment cost (OPEX). CAPEX for pipe construction and treatment line addition are not explicitly modelled. The sewage flowrate $Q^{\text {in }}$ and quality $c_{j}{ }^{\text {in }}$ are specified and the local discharge limits $\mathrm{c}_{\mathrm{j}}{ }^{\text {out,max }}$ must not be violated. Customers generate a revenue $\mathrm{B}_{\mathrm{k}}$. The contaminants considered are Suspended Solids (SS), Biochemical Oxygen Demand (BOD), Chemical Oxygen Demand (COD), Total Nitrogen (TN) and Phosphorous (P).

The WWTP of the case study consists of three treatment lines delivering water of different quality (fixed removal efficiency $\rho_{\mathrm{j}}$ ) at different operational expenses: A Membrane Bioreactor (25,000 m3/day), an Integrated Fixed-Film Activated Sludge (25,000 $\mathrm{m}^{3} /$ day) and a Traditional Wastewater Treatment Line $\left(60,000 \mathrm{~m}^{3} /\right.$ day). These treatment processes can be either operated in standard operation or, at a higher expense, in nutrient removal (NR) mode clearing additionally Nitrogen and Phosphorus from the sewage.

\section{Water Exchange Model}

This model is based on the one by Somoza-Tornos et al. (2019), which we extend with the possibility to add new treatment lines in reaction to fluctuations in the market demand for regenerated water. The water exchange model balances the inlet and outlet of the treatment units while treating the product flows $Q$ and contamination $c_{j}$ concentration as a substitution variable in order to avoid bilinear terms. Nonlinearities emerging from bilinear terms involving binary variables are handled through the introduction of Big-M constraints. This allows us to perform a more complex analysis without losing model accuracy.

The objective function to be minimized is the OPEX of the WWTP and stated according to Equation (1). It comprises the generated revenue and the operational expenses for running the treatment lines. Moreover, it includes a penalty $\mathrm{P}_{\mathrm{k}}$ for failing to supply contracted customers.

$$
\text { OPEX }=\left(-\sum_{k}\left(Q_{k} \cdot B_{k}-\left(D_{k}-Q_{k}\right) \cdot P_{k}\right)+\sum_{i, k, e} \operatorname{Cost}_{i, k, e}^{O p}\right) \div Q^{i n}
$$




\section{Results and Discussion}

From the optimal supply network shown in Figure 1 it can be seen that some of the identified customers can be profitably supplied by the regenerated water. Customers 4,5 and 9 proved to have too high quality demands and generate too little revenue to be considered profitable customers. By evaluating the economic objective function we obtain a reduced water treatment cost of $0.312 € / \mathrm{m}^{3}$ from originally $0.404 € / \mathrm{m}^{3}$ of treated wastewater. The associated freshwater replacement is $14,256 \mathrm{~m}^{3} /$ day. A sensitivity analysis of the incoming sewage stream and contamination (10\% perturbation) yields a range of costs from $0.293 € / \mathrm{m}^{3}$ to $0.515 € / \mathrm{m}^{3}$.

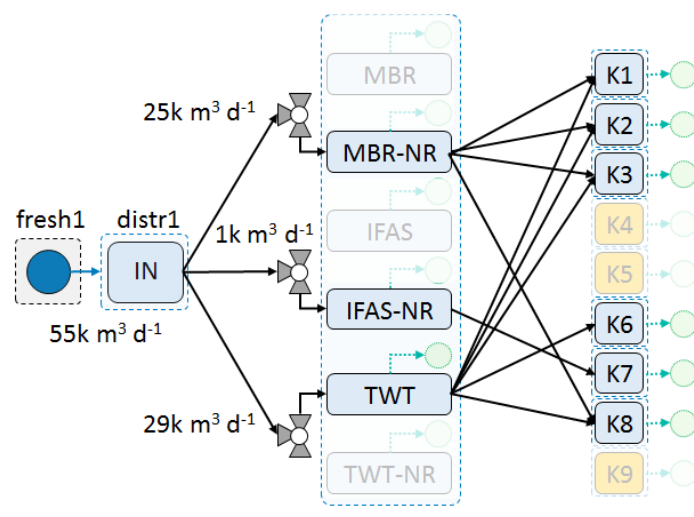

Figure 1 - Optimal network solution for nominal operating condition.

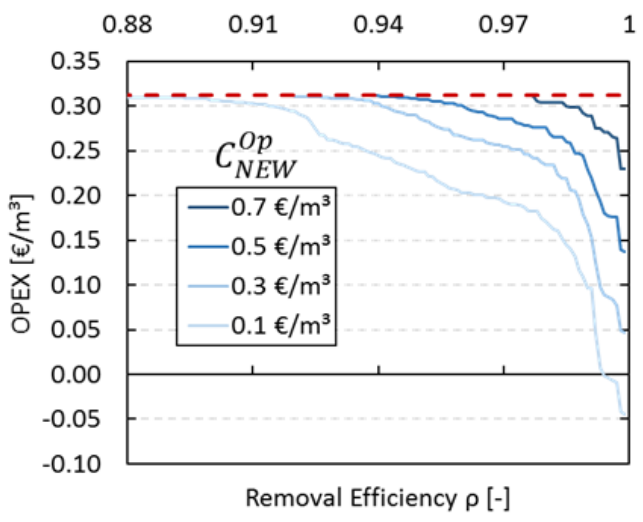

Figure 2- Barriers for treated water cost when adding a new treatment line $\left(25,000 \mathrm{~m}^{3} /\right.$ day $)$.

By considering the construction of an additional treatment line it is possible to generate further benefit. For fixed operational cost of the new treatment line we draw the resulting minimal OPEX depending on the removal efficiency $\left(\rho_{j}=\rho\right)$. Figure 2 shows the OPEX for four selected values of treatment costs. In certain favorable scenarios, a negative OPEX is obtained, which corresponds to a profit generating operation. Based on these results, decisions on potential retrofitting of the WWTP can be made. Despite the simplifications made on the installation costs and the functionality of the treatment processes, the results can be efficiently generated by a new MILP formulation and may be utilized as initial points for more detailed investigations.

\section{Conclusions}

The findings of this study expose the unexplored potential in the use of regenerated water according to circular economy principles. WWTPs and authorities should consider the possibility of adapting and retrofitting their local water network to make use of that potential. Future work will be directed towards finding feasible balanced network solutions when taking into account the objectives of all the actors involved.

\section{Acknowledgements}

Financial support received from the Spanish "Ministerio de Economía, Industria y Competitividad" and the European Regional Development Fund, both funding the research Project AIMS (DPI2017-87435-R) is fully acknowledged.

\section{References}

Guerra-Rodríguez, S., Oulego, P., Rodríguez, E., Singh, D., Rodríguez-Chueca, J. 2020. "Towards the implementation of circular economy in the wastewater sector: Challenges and opportunities". Water (Switzerland) 12. https://doi.org/10.3390/w12051431

Karuppiah, R. and Grossmann, I. E. 2006. "Global optimization for the synthesis of integrated water systems in chemical processes". Computers and Chemical Engineering, 30(4), 650-673. https://doi.org/10.1016/j.compchemeng.2005.11.005

Salas, D., Van, K. C., Aussel, D., and Montastruc, L. 2020. "Optimal design of exchange networks with blind inputs and its application to Eco-industrial parks". Computers and Chemical Engineering, $143 \mathrm{https}: / /$ doi.org/10.1016/j.compchemeng.2020.107053

Somoza-Tornos, A., Rives-Jiménez, M., Espuña, A., and Graells, M. 2019. "A Circular Economy Approach to the Design of a Water Network Targeting the Use of Regenerated Water". Computer Aided Chemical Engineering (Vol. 47, pp. 119-124). Elsevier B.V. https://doi.org/10.1016/B978-0-12-818597-1.50020-5 